\title{
PEMBELAJARAN AKTIF TIPE LEARNING TOURNAMENT BERBASIS LOCAL WISDOM KABUPATEN FLORES TIMUR UNTUK MENINGKATKAN PEMAHAMAN KONSEP SISWA
}

\author{
Maria Ursula Jawa Mukin ${ }^{a}$, Alfons Bunga Naen ${ }^{\text {b) }}$, Godelfridus H. Lamanepa ${ }^{\text {c) }}$, \\ Rosenti Pasaribu ${ }^{\text {d) }}$, Tapin Yohanes ${ }^{\mathrm{e})}$, Maria Irma Ina Lipat ${ }^{\mathrm{a})}$

\begin{abstract}
Program Studi Pendidikan Fisika, Fakultas Keguruan dan Ilmu Pendidikan, Universitas Katolik Widya Mandira, Jalan. Jend. A. Yani no 50-52 Kupang, Indonesia.
\end{abstract}

Email: ${ }^{\text {a) }}$ mariamukinym@ gmail.com, b) alfonsbunganaen@unwira.ac.id, ${ }^{\text {c) }}$ godelfriduslamnepa@ unwira.ac.id,

d)rosentipasribu@unwira.ac.id, ${ }^{\mathrm{e})}$ tapinyohanes@unwira.ac.id

\begin{abstract}
Abstrak
Kegiatan Penelitian ini bertujuan untuk melihat penerapan model pembelajaran aktif tipe learning tournament berbasis local wisdom untuk meningkatkan pemahaman konsep siswa. pemahaman konsep yang mau di lihat meliputi interpreting, explaining, classifying, examplyfifying, inferring, summarizing dan compairing. Pembelajaran aktif tipe learning tournament mengajak siswa untuk belajar secara kooperatif, kolaboratif, kompetitif dan menciptakan kondisi pembelajaran lebih santai. Pembelajaran aktif menciptakan suasana belajar sehingga dapat meningkatkan kemampuan pemahaman konsep dan penguatan karakter siswa. desain penelitian yang digunakan adalah One - Group Pretest- Posttest Design Teknik pengumpulan data dalam penelitian ini menggunakan tes untuk menjaring data kemampuan pemahaman konsep baik sebelum maupun sesudah pembelajaran. sementara itu untuk nilai hasil pre-test dan post-test yang diberikan menjadi bahan pertimbangan lain dalam menentukan peningkatan kemampuan pemahaman konsep dan penguatan karakter siswa. setelah data-data tersebut terkumpul, maka tahap selanjutnya adalah analisis. dimana Teknik analisis data yang digunakan adalah uji Gain. berdasarkan hasil analisis pada tes pemahaman konsep yang menerapkan pembelajaran Aktif tipe learning Tournament Berbasis Local Wisdom, dengan menggunakan uji n-gain secara keseluruhan siswa mengalami peningkatan. peningkatan pada pemahaman konsep sebesar 0,82 dan dikategorikan tinggi.
\end{abstract}

Kata-kata kunci : Aktif Tipe Learning Tournament, local wisdom, Pemahaman konsep

\begin{abstract}
This research activity aims to see the application of active learning models based on local wisdom type learning tournament to improve students' understanding of concepts. Understanding the ideas to be seen include interpreting, explaining, classifying, exemplifying, inferring, summarizing, and comparing. Active learning type learning tournament invites students to learn cooperatively, collaboratively, competitively and create more relaxed learning conditions. Active learning creates a learning atmosphere to improve understanding concepts and strengthen students' character. The data collection process in this study uses tests to capture data of understanding concepts, both before and after learning. Meanwhile, the pre-test and post-test results' value is another consideration in determining the increase
\end{abstract}


in the ability to understand concepts and strengthen student character. After the data is collected, the next step is analysis. Where the data analysis technique used is the Gain test. Based on the analysis results on the conceptual understanding test that applies the Active Learning Type Learning Tournament Based on Local Wisdom, using the n-gain test overall students have increased. The increase in concept comprehension was 0.82 and categorized high.

Keywords: Active Learning Type Learning Tournament, Local Wisdom, Concept Understanding

\section{PENDAHULUAN}

Pesatnya perkembangan sains dan teknologi dalam kehidupan masyarakat pada saat ini menuntut manusia untuk semakin berinovasi dalam segala aspek kehidupan. Besarnya peran fisika dalam menunjang perkembangan teknologi menuntut pengajaran fisika untuk berorientasi pada pencapaian hasil belajar yang optimal. Pemahaman konsep fisika yaitu mengkaitkan kemampuan abstrak dengan hasil pengamatan yang dilakukanya [1]. Pemahaman konsep fisika perlu didasarkan pada keterkaitan antara konsep yang diperoleh secara empiris dengan konsep yang bersifat teoritik sehingga siswa memperoleh kebenaran yang lebih mantap. Selain memperkaya pemahaman konsep, kegiatan pembelajaran di sekolah dapat membantu pembentukan karakter, kepribadian, dan kebiasaan untuk meningkatkan kualitas hidup [2].

Berdasarkan hasil observasi dan wawancara di beberapa SMA dikabuaten flores timur pada tanggal 24-28 september 2019 pembelajaran fisika sangat berkaitan erat dengan kehidupan seharihari termasuk hal yang sudah menjadi tradisi yang membudaya pada suatu daerah. Hal ini menjadi alasan bahwa konsep fisika bisa diterapkan dan ditemukan siswa dalam kehidupannya sehari-hari, misalkan melalui permainan tradisional, tarian daerah, dan ceritera rakyat. Proses pembelajaran yang mengakomodasi hal-hal seperti ini masih jarang dilaksanakan di sekolah-sekolah. Dalam pembelajaran fisika sangat bagus ketika mengunakan budaya lokal (local wisdom) sebagai media dan alat peraga pembelajaran. Selain siswa dapat menghubungkan ilmu dengan kehidupan sehari-hari, siswa juga dapat mepelajari dan menghargai budayanya sendiri, sehingga kearifan lokal tetap terjaga. Pembelajaran fisika dapat dilakukan dengan mengintegrasikan fisika dengan budaya setempat, karena pada dasarnya fisika adalah ilmu yang dapat diterapkan dalam kehidupan sehari-hari. Salah satu contoh fisika dalam kehidupan sehari-hari yang mengintegrasikan budaya lokal adalah permainan "kebetok". Permainan "kebetok" merupakan permaianan yang sering dimainkan oleh anak-anak di kecamatan adonara tengah kabupaten Flores Timur propinsi Nusa Tenggara Timur.

Berdasarkan hasil observasi dan wawancara di beberapa SMA dikabuaten flores timur pada tanggal 24-28 september 2019. Permainan "kebetok" merupakan permaianan yang sering dimainkan oleh anak-anak di kecamatan adonara tengah kabupaten Flores Timur propinsi Nusa Tenggara Timur. Permainan ini dimainkan oleh dua kelompok anak, dengan menggunakan dua potongan kayu (potongan panjang dengan ukuran kurang lebih $30 \mathrm{~cm}$, dan ukuran pendek dengan ukuran kurang lebih $10 \mathrm{~cm}$ ). Cara memainkan permainan ini dengan cara meletakan potongan pendek di atas lubang tanah kemudian dicungkil dengan batang panjang dan dipukul. Permainan masyarakat Adonara Tengah yang bisa diterapkan dalam pembelajaran fisika selain "Kebetok", adalah Permainan "Tubo Ua", dan permainan "Keso". Permainan "Tubo Ua", mirip dengan tarik tambang, hanya pada saat bermain dilengkapi dengan syair-syair sebagai penyemangat. Sedangkan permainan "keso" dilakukan dengan cara memindahkan buah keso menggunakan telapak kaki samping bagian dalam agar dapat mengenai keso lawan. Ketiga jenis permainan rakyat ini, diterapkan dalam pembelajaran fisika untuk memperoleh pengetahuan tentang materi Dinamika Gerak Benda (meliputi Gaya, Gerak Lurus Berubah Beraturan, Gerak Parabola, Impuls dan Momentum), di samping itu keterampilan motorik, dan sikap siswa juga dilatih selama proses pembelajaran dengan tetap melestarikan budaya setempat. Pemanfaatan local wisdom dalam pembelajaran fisika serupa dengan melakukan eksperimen di dalam laboratorium. Pembelajaran fisika berbasis eksperimen dapat menjadi solusi dalam mengatasi kemampuan keterampilan proses sains yang rendah [3].

Local wisdom satu daerah dapat diterapkan dalam pembelajaran [4]. Hal ini dapat menunjang program pelestarian local daerahnya. Salah satu hal yang mempengaruhi keberhasilan pembelajaran 
adalah prosesnya. Proses pembelajaran yang dipersiapakan tepat dan matang memberikan peluang yang besar terhadap pencapaian tujuan pembelajaran. Model pembelajran merupakan salah satu faktor yang dapat menunjang peroses pembelajaran. Oleh karena itu dalam memilih model pembelajaran guru harus mempertimbangkan kecocokan antara model dengan materi dan karakter siswa dan kompetensi yang ingin dicapai. Pembelajaran yang berlangsung aktif dan kolaboratif dapat menumbuhkan kreativitas yang lebih signifikan daripada menggunakan metode konvensional yang menempatkan siswa sebagai penerima informasi dari guru [5]. Pembelajaran aktif memicu siswa untuk menjadi subjek pembelajaran yang aktif dan kolaboratif wisdom sehingga tidak tergeser oleh perkembangan zaman [6]. Oleh karena itu, dengan mengintegrasikan local wisdom, maka pengetahuan dan nilai kebudayaan dapat disampaikan kepada siswa sebagai efek pengiring. Hasilnya siswa tidak meninggalkan local wisdom yang dimiliki oleh dalam pembelajaran. Salah satu tipe pembelajaran aktif yang memenuhi hal tersebut adalah learning tournament.

Pembelajaran aktif tipe learning tournament memiliki potensi yang besar dalam pencapaian hasil pembelajaran. Hal ini dikarenakan siswa dipacu agar secara aktif saling berkomunikasi secara kolaboratif dan terorganisir untuk berfikir bersama dalam menemukan solusi pemecahan permasalahan. Beberapa keterampilan tindakan yang dilakukan siswa seperti komunikasi, kolaborasi, penemuan tim, belajar berdasarkan pertanyaan, sistem berfikir, pemecahan masalah, refleksi, dan pembelajaran terorganisasi memberikan benefit yang tinggi [7]. Selain tujuan pembelajaran dapat tercapai dengan optimal, penerapan pembelajaran aktif tipe learning tournament berpotensi untuk menyiapkan siswa agar memiliki keterampilan yang diperlukan untuk hidup bermasyarakat.

\section{METODOLOGI}

Desain penelitian yang digunakan adalah One-Group Pretest-Posttest Design yang merupakan bagian dari Quasi Experimental Design [8]. Penelitian ini tidak menggunakan kelas perbandingan, karena telah menggunakan tes awal sehingga besar pengaruh atau pengaruh penggunaan Model Pembelajaran Aktif Tipe Learning Tournament dapat diketahui dengan pasti [9].

Keterangan:

\begin{tabular}{|l|c|c|}
\hline O-1 & $\mathrm{X}$ & $\mathrm{O}-2$ \\
\hline
\end{tabular}

O-1 : Pre-Test

O-2 : Post-Test

X : Perlakuan dengan menerapkan Model Pembelajaran Aktif Tipe Learning Tournament

Menghitung nilai Pre-Test dan Post-Test untuk pemahaman konsep mahasiswa menggunakan rumus [10]:

$$
\text { Nilai }=\frac{\text { Jumlah Jawaban Benar }}{\text { Jawaban Total }} \times 100
$$

Untuk mengetahui peningkatan pemahaman konsep siswa sesudah mengikuti kegiatan pembelajran menggunakan rumus N-Gain, sebagai berikut:

$$
\text { Gain Standar }=\frac{\text { skor post test }- \text { skor pre test }}{\text { skor maksimum- skor pre test }}
$$

Berdasarkan hasil skor gain yang diperoleh selanjutnya dikategorikan ke dalam kriteria-kriteria seperti pada TABEL 1.

TABEL 1. Klasifikasi Faktor (g)

\begin{tabular}{cc}
\hline IInterval Faktor $(\mathbf{g})$ & Kriteria \\
\hline$>0,70$ & Tinggi \\
$0,30 \leq(\mathrm{g}) \leq 0,70$ & Sedang \\
$(\mathrm{g})<0,30$ & Rendah \\
\hline
\end{tabular}




\section{HASIL DAN PEMBAHASAN}

\section{Hasil Pretest dan Posttest Pemahaman Konsep}

Setelah dilaksanakan Pretest dan Posttest hasil perhitungannganya direkap pada TABEL 2.

TABEL 2. Ringkasan Data Pemahaman Konsep

\begin{tabular}{lc}
\hline \multicolumn{1}{c}{ Aspek } & Keterangan \\
\hline Jumlah siswa & 20 \\
Nilai tertinggi Pretest & 28 \\
Nilai tertendah Pretest & 15,5 \\
Nilai tertinggi Posttest & 90,51 \\
Nilai tertendah Posttest & 68 \\
\hline
\end{tabular}

\section{Peningkatan Pemahaman Konsep}

Untuk menghitung peningkatan pemahaman konsep siswa dapat dianaliss dengan uji $n$-gain. Ringkasan data hasil tes pemahaman konsep siswa dapat dilihat pada TABEL 3.

Tabel 3. Data Peningkatan Pemahaman Konsep

\begin{tabular}{cccc}
\hline No Urut Siswa & Tes Awal & Tes Akhir & Peningkatan \\
\hline 1 & 25 & 90 & 0,87 \\
2 & 23 & 90 & 0,87 \\
3 & 15,5 & 75 & 0,70 \\
4 & 28 & 85,5 & 0,80 \\
5 & 26 & 90,51 & 0,87 \\
6 & 27 & 80,5 & 0,73 \\
7 & 26,5 & 87 & 0,82 \\
8 & 27,5 & 89 & 0,85 \\
9 & 27 & 90,5 & 0,87 \\
10 & 25,5 & 80 & 0,73 \\
11 & 15,5 & 68 & 0,62 \\
12 & 25 & 90,5 & 0,87 \\
13 & 23,5 & 85 & 0,80 \\
14 & 20 & 85 & 0,81 \\
15 & 25 & 85,5 & 0,81 \\
16 & 27,8 & 90 & 0,86 \\
17 & 28 & 90,5 & 0,87 \\
18 & 25 & 90,5 & 0,87 \\
19 & 26,5 & 90,5 & 0,87 \\
20 & 26 & 85,5 & 0,80 \\
Rata-rata Skor & $\mathbf{2 4 , 6 7}$ & $\mathbf{8 5 , 9 5}$ & $\mathbf{0 , 8 2}$ \\
\hline
\end{tabular}

Pada TABEL 4 dapat diketahui skor awal dan akhir siswa adalah 24,67 dan 85,95. Rata - rata skor peningkatan 0,82 dalam kategori tinggi.Pada pemahaman konsep siswa mengerjakan soal tes pemahaman konsep secara individu. Dengan memperhatikan nilai n- gain ini sebesar 0,82 artinya bahwa secara individual pemahaman konsep siswa terkait dengan materi Dinamika Gerak Benda yang meliputi Gaya, Gerak Lurus Berubah Beraturan, Gerak Parabola, Impuls dan momentum sudah dikuasai dan dipahami secara baik. Pemahaman dan Penguasaan konsep yang baik meliputi kemampuan siswa dalam melakukan interprestasi, memberikan contoh penerapan, melakukan klasifikasi, membandingkan, melakukan generalisasi, menjelaskan, dan menyimpulkan. Kemampuan ini seperti tertuang dalam indikator pemahaman konsep sebagai berikut: Interpretasi(interpreting), Mencontohkan(exemplifying),Mengklasifikasikan(classifying),menggeneralisasikan(summarizing),me nggeneralisasikan(summarizing)Membandingkan(comparing)danmenjelaskan(explaini).

Pemahaman konsep yang baik dari siswa kelas 11 IPA SMA Negeri Adonara Tengah yang berjumlah 20 siswa juga dapat dilihat dari perolehan nilai rata-rata post test 85,95 dengan nilai terendah 68 dan tertinggi 90,51. Hal ini berarti aktivitas siswa selama pembelajaran yang 
menerapkan pembelajaran Aktif Tipe Learning Tournament Berbasis Local Wisdom, sesuai skenario pembelajaraaan yang disiapkan. Hal ini sejalan dengan teori pembelajaran aktif tipe learning tournament yang lebih pada mengajak siswa untuk belajar secara kooperatif, kolaboratif, kompetitif, dan menciptakan kondisi pembelajaran lebih santai. Pembelajaran aktif menciptakan suasana belajar lebih menekankan keintiman yang melekat dengan janji keterlibatan siswa dan peningkatan hasil belajar.

\section{SIMPULAN}

Adapun kesimpulan dari penelitian ini adalah: Model Pembelajaran Aktif Tipe Learning Tournament Berbasis Local Wisdom dapat meningkatkan kemampuan pemahaman konsep dan penguatan karakter siswa. Berdasarkan hasil analisis data rata-rata skor peningkatan pemahaman konsep adalah 0,82 dalam kategori tinggi

\section{UCAPAN TERIMAKASIH}

Terima kasih untuk semua pihak yang sudah membantu dalam penelitian dan penulisan artikel.

1. Universitas Katolik Widyamandira sebagai sumber dana penelitian.

2. Kepala sekolah dan guru fisika SMA Negeri I Adonara Tengah yang sudah mengijinkan tim untuk melaksanakan penelitian.

3. Siswa/siswi kelas XI MIA SMA Negeri I Adonara Tengah yang telah bersedia menjadi subjek penelitian.

4. Kepada semua tim penelitian.

\section{REFERENSI}

[1] Mutlu Ayfer \& Burcin Acar Sesen, "Development of a two-tier diagnostic test to assess undergraduates'understanding of some chemistry concepts: Procedia - Social and Behavioral Sciences, vol. 174, pp. 629-635, 2015.

[2] A. Anita and F. Novianty, "The Students' Characters Analysis in Physics Learning Process", JPPPF (Jurnal Penelitian dan Pengembangan Pendidikan Fisika), vol. 6, no. 1, pp. 75 - 80, Jun. 2020.

[3] R. Athiyyah, T. Al Farizi, and D. Nanto, "Improvement of Science Process Skills Through Sound Variable Intensity Level Tool Kit", JPPPF (Jurnal Penelitian dan Pengembangan Pendidikan Fisika), vol. 6, no. 1, pp. 89 - 96, Jun. 2020.

[4] A. S. Ardan et al., "Needs Assessment to Development of Biology Textbook for High School Class X-Based the Local Wisdom of Timor," International Education Studies, vol. 8, no. 4, pp. 52-59, 2018.

[5] A. F. Morales \& M. C. M. Toledano, "Developing Creativity and Innovation through Collaborative Projects. Proceedings of the 2012 Conference on Creativity in Higher Education," Finland, vol. 2, no. 3, pp. 70-82, 2012.

[6] I. S. Utami, M. Vitasari, I. Langitasari, I. Sugihartono, and Y. Rahmawati, "The Local Wisdom-Based STEM Worksheet to Enhance the Conceptual Understanding of Pre-service Physics Teacher", JPPPF (Jurnal Penelitian dan Pengembangan Pendidikan Fisika), vol. 6, no. 1, pp. 97 - 104, Jun. 2020.

[7] A. Ninck, "Teaching and Learning for Innovation," Proceedings of the 2012 Conference on Creativity in Higher Education, Finland, vol. 2, no. 3, pp. 9-19, 2012.

[8] Sugiyono, 2009, "Metode Penelitian Kuantitatif, Kualitatif dan R\&D”, Bandung : Alfabeta. 
[9] R. Haryadi and H. Pujiastuti, "Discovery Learning based on Natural Phenomena to Improve Students' Science Process Skills", JPPPF (Jurnal Penelitian dan Pengembangan Pendidikan Fisika), vol. 5, no. 2, pp. 183 - 192, Dec. 2019.

[10] Trianto. 2012. "Model Pembelajaran Terpadu", Jakarta: PT Bumi Aksara. 